\title{
Comparative analysis for the corrosion susceptibility of copper alloys in sandy soil
}

\author{
Mouhsine Galai ${ }^{\dagger}$, Hanane Benqlilou ${ }^{2}$, Mohamed Ebn Touhami ${ }^{1}$, Tounsi Belhaj ${ }^{2}$, \\ Khalifa Berrami ${ }^{2}$, Hassan El Kafssaoui ${ }^{1}$ \\ ${ }^{1}$ Laboratory of Materials Engineering and Environment: Modeling and Application, Faculty of Science, Ibn Tofail University, BP. 133-14000, Kenitra, Morocco \\ ${ }^{2}$ International Institute for Water and Sanitation (IEA), National office of Electricity and the Potable Water, BP. 10220, Rabat, Morocco
}

\begin{abstract}
Corrosion of copper alloys (copper, bronze and brass) in soil was evaluated at ambient temperature using various methods such as electrochemical impedance spectroscopy (EIS), polarization curves and Scanning Electron Microscopy (SEM) coupled with Energy Dispersive Spectroscopy microanalysis measurements. Three equivalent circuits were separately used to interpret the obtained impedance spectra. The EIS measurements indicated that the polarization resistance of all electrodes increases with increasing the immersion time. SEM showed a presence of three layers of corrosion products with various composition and morphology covering each electrode. In addition, it was found that at $20 \%$ of moisture content the $R_{p}$ values and the current density of all electrodes in the studied soil give the following order: copper $>$ bronze $>$ brass. Good consistency between the data obtained from EIS and PP measurements was observed.
\end{abstract}

Keywords: Copper alloys, Corrosion, Electrochemical methods, Soil

\section{Introduction}

Copper and its alloys have been used for more than 10,000 $\mathrm{y}$ and are widely used in various industrial fields thanks to their interesting properties. In particular, these properties are high electrical and thermal conductivities, good chemical weldability and especially, the good resistance to corrosion. In addition, the copper and brass are used in the sanitary industry to make drinking water pipes and plumbing devices.

Copper present an excellent resistance to corrosion in unpolluted air and drinking water. However, copper materials can undergo significant corrosion under various conditions, like the presence of sulphates, chlorides or nitrates. It is therefore important to find the right copper alloy by considering the environmental conditions to which it will be exposed [1].

The intensity of dezincification of brass is very closely related to the structure of the alloy which is controlled by composition. As might be expected the resistance to this dezincification increases with copper contained in brass, but this relationship is not linear. Many positive changes in performance take place when the structure changes from all-beta to $(\alpha+\beta)$ duplex and from duplex to all-alpha phase. The alloys that contain less than $15 \%$ Zn rarely undergo dezincification [2, 3].

Bronze like brass is a common structural material and was one of the first alloys developed by ancient metal workers. Bronze is a copper alloy containing tin, generally in the 1 to $10 \%$ range. The addition of tin increases the bronze hardness making it more resistant to wear when compared with pure copper metal [4].

Corrosion means a deterioration of a metal or properties which defines this metal due to an environmental reaction. The corrosion in soil is a strongly intricate phenomenon with a variety of factors involved like soil particle size, moisture content, degree of aeration, $\mathrm{pH}$, redox potential, resistivity, soluble ionic species (salts) and microbiological activity. Many surveys of the degradation of metal used in plumbing devices that depend on the soil type reveal soil parameters such as soil texture, soil acidity, and the quantities of soluble salts like $\mathrm{Cl}^{-}$and $\mathrm{SO}_{4}{ }^{2-}$ which foster the corrosion of metal objects [5-8].

In the present study, the Essaouira site was the location where a complaint was made about the corrosion of fitting brass (gate valves) which connects the PVC's conduits. Indeed, because
This is an Open Access article distributed under the terms of the Creative Commons Attribution Non-Commercial License (http://creativecommons.org/licenses/by-nc/3.0/) which permits unrestricted non-commercial use, distribution, and reproduction in any medium, provided the original work is properly cited.

Copyright (C) 2018 Korean Society of Environmental Engineers
Received June 20, 2017 Accepted January 9, 2018

${ }^{\dagger}$ Corresponding author

Email: galaimouhsine@gmail.com

Tel: +212-677235695

ORCID: 0000-0003-3199-9403 
of this problem, thus a convention with The National Office of Electricity and the Drinking Water (ONEE) and our laboratory have been made to study the corrosion of gate valves in other sites in Morocco. In various studies [9-12] the authors were interested in steels pipeline corrosion in soil. But the ONEE company required to use the copper alloys as a gate valve. Therefore, our mission is to investigate the effect of soil on the corrosion behavior of three materials; copper, bronze and brass in sandy soil from Essaouira city of Morocco at ambient temperature $\left(25 \pm 2^{\circ} \mathrm{C}\right)$.

\section{Materials and Methods}

\subsection{Soil Sample Preparation}

A fraction of the soil was taken from $1 \mathrm{~m}$ deep under the ground at collected in a suburban area of Essaouira site in Morocco was dried at $105^{\circ} \mathrm{C}$ for $24 \mathrm{~h}$ and then left in the desiccator (DURAB, Germany). Soil sampling and analysis is performed following the procedures described elsewhere [13].

Table 1 gives the concentrations of the elements and the texture that have been analyzed in the original soil sample. So, from the texture, we can classify the sample as a sandy soil.

In addition, the electrochemical cell which was specifically designed for this study is represented in Fig. 1 respecting the literature [14].

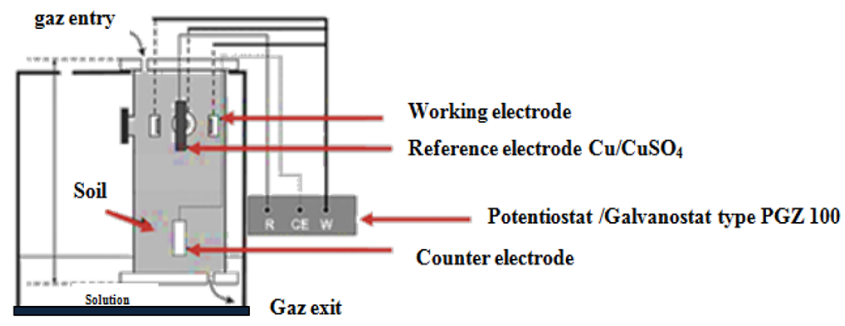

Fig. 1. Electrochemical system designed for the study of copper alloy in Essaouira soil.
Each soil sample was compacted manually in the electrochemical cell by applying a Proctor Compactor that consists of $3 \mathrm{~kg}$ soil which is dropped from a height of $150 \mathrm{~mm}$. The atmosphere inside the cell was constantly renewed via a flow of reconstituted air $\left(80 \%\right.$ of $\mathrm{N}_{2}$ and $20 \%$ of $\mathrm{O}_{2}$ ) which circulated on the soil surface in the upper part of the cell.

\subsubsection{Composition of metallic materials}

The chemical composition of copper, bronze, and brass are presented in Table 2. Chemical composition analysis was performed by optical emission spectrometer (BRUKER, French).

The different material specimens encapsulated by an epoxy-resin were used as a working electrode with an exposed area of $0.78 \mathrm{~cm}^{2}$. Before each test, the sample was polished with abrasive paper up to 1,200 grit, rinsed with deionized water, degreased with ethanol (EMSURE, Reag. Ph Eur made in Germany) and finally dried in air.

\subsection{Electrochemical Methods}

\subsubsection{Electrochemical impedance spectroscopy}

Electrochemical impedance spectroscopy (EIS) measurements were performed using a transfer function analyzer (Volta Lab PGZ 100, Radiometer Analytical, French) frequency response analyzer in a frequency range of $100 \mathrm{kHz}$ to $10 \mathrm{mHz}$ with 10 points per decade with a small amplitude a.c. signal $(10 \mathrm{mV})$. The EIS diagrams were done in the Nyquist representation. The results were then analyzed according to an equivalent electrical circuit using Bouckamp software [15].

\subsubsection{Polarization tests}

The counter electrode was a stainless steel plate with $9 \mathrm{~cm}^{2}$ of surface area whereas reference electrodes were copper-copper sulphate electrodes $\mathrm{Cu} / \mathrm{CuSO}_{4}$ (ADCA SA, French) with $(+0.316$ $\mathrm{V} / \mathrm{SHE}$ at $25^{\circ} \mathrm{C}$ ) which were commonly used in the field. In the following sections of this article, all potentials are presented according to this reference electrode.

In addition, the working electrode was immersed in the soil during $21 \mathrm{~d}$ until a steady state open circuit potential $\left(E_{\text {оср }}\right)$

Table 1. Main features of Essaouira Soil As Received from the Field and Properties of the Soils

Concentration of various ions in aqueous extract $(\mathrm{mg} / \mathrm{L})$

\begin{tabular}{cccccc}
\hline $\mathrm{Ca}^{2+}$ & $\mathrm{Mg}^{2+}$ & $\mathrm{Cl}^{-}$ & $\mathrm{SO}_{4}^{2-}$ & $\mathrm{Na}^{+}$ & $\mathrm{K}^{+}$ \\
\hline 36 & 15.6 & 68.7 & 61.5 & 52.67 & 19.9 \\
\hline Essaouirasoil texture & & & & & \\
\hline Clay & Silt & Sand & $\mathrm{pH}$ & Moisture(\%wt) & $\mathrm{CE}(\mathrm{mS} / \mathrm{cm})$ \\
\hline 8.3 & 13.6 & 78.1 & $6.85 \pm 0.2$ & 20 & 0.548 \\
\hline
\end{tabular}

Table 2. Chemical Compositions of Different Electrodes with Addition Element

\begin{tabular}{ccccccccccccccc}
\hline \multirow{2}{*}{$\begin{array}{c}\text { Copper } \\
\text { alloys }\end{array}$} & \multicolumn{1}{c}{$\boldsymbol{\alpha}$ phase } & $\mathbf{C u}$ & $\mathbf{Z n}$ & $\mathbf{P b}$ & $\mathbf{S n}$ & $\mathbf{F e}$ & $\mathbf{A l}$ & $\mathbf{N i}$ & As & $\mathbf{M n}$ & $\mathbf{P}$ & $\mathbf{S i}$ & $\mathbf{S b}$ \\
\hline Brass & 91.27 & 70 & 21.95 & 1.27 & 0.57 & 1.71 & 3.675 & 0.45 & 0.010 & 0.1365 & 0.00165 & 0.0345 & 0.03 \\
Bronze & - & 85.224 & 5.05 & 3.88 & 4.875 & 0.0615 & - & 0.705 & 0.016 & - & 0.01 & - & 0.099 \\
Copper & - & 99.976 & 0.0031 & 0.0022 & & 0.0022 & - & 0.0054 & - & - & 0.0008 & - & - \\
\hline
\end{tabular}


was reached. The steady-state polarization curves were recorded potentiodynamically using a Volta Lab PGZ 100 and controlled by a personal computer. The cathodic polarization curve was recorded by polarization from $\left(E_{\text {оср }}\right)$ to negative direction $(-1,500$ $\mathrm{mV} / \mathrm{Cu} / \mathrm{CuCuSO}_{4}$ ) under potentiodynamic conditions corresponding to $1 \mathrm{mVS}^{-1}$ (scan rate). After this scan, the anodic polarization curve was recorded by polarization from $\left(E_{\text {оср }}\right)$ to positive direction $\left(1,200 \mathrm{mV} / \mathrm{Cu} / \mathrm{CuCuSO}_{4}\right)$ under the same conditions as said before. The corrosion kinetic parameters were evaluated again by means of non-linear least square method and by applying Eq. (1) using origin software. Nonetheless, for this calculation, the potential interval chosen was limited to $\pm 0.100 \mathrm{~V}$ beside $E_{\text {corr }}$, and a significant systematic divergence was sometimes noticed for both cathodic and anodic branches.

$$
\begin{aligned}
i & =i_{a}+i_{b} \\
& =i_{\text {corr }} \times\left\{\exp \left[b_{a} \times\left(E-E_{\text {corr }}\right)\right]-\exp \left[b_{c} \times\left(E-E_{\text {corr }}\right)\right]\right\}
\end{aligned}
$$

Where $i_{\text {corr }}$ is the corrosion current density and Tafel plots: $b_{a}$ (anodic) \& $b_{c}$ (cathodic) which are attached to Tafel slopes $\beta$ and expressed in logarithmic scale by the following equation:

$$
\beta=\frac{\ln (10)}{b}=\frac{2.303}{b}
$$

\subsection{Scanning Electron Microscopy (SEM)}

Examination of all studied electrodes after exposure into the sandy soil after a hold time immersion of $130 \mathrm{~d}$, was carried out using scanning electron microscopy (SEM; JOEL JSM-5500 made in Japan) before observation these specimens were rinsed thoroughly in a nonreactive solvent (alcohol) to prevent further corrosion.

\section{Results and Discussion}

\subsection{EIS Measurements}

The EIS measurements were carried out at corrosion potential. The Nyquist diagrams were registered for different electrodes in Essaouira soil and at different times from 1 to $21 \mathrm{~d}$ at $20 \%$ of moisture content as shown in Fig. 3 and Fig. 5.

Three equivalent circuits were obtained: the first is for the corrosion of brass in Essaouira soil (Fig. 2(a)) the second (Fig. 2(b)) is for the corrosion of copper whereas the last one is for the corrosion of bronze in the same soils (Fig. 2(c)).

In the case of brass, equivalent circuits consist of solution resistance $R_{S}$ connected in series with two time constants R1[Q1(R2Q2)]. The $Q$ symbol mean the possibility of a non-ideal capacitance (CPE, constant phase element) where $n$ is the variable. The impedance of the CPE is given by the following equation [16]:

$$
Q=Z_{C P E}(\omega)=\left[C j \omega^{n}\right]^{-1}
$$

For $\mathrm{n}=1$, the $Q$ element reduces to a capacitor with a capacitance $C$ and, for $\mathrm{n}=0$, to a simple resistor. Firstly, the process $\left(R_{f}, Q_{f}\right)$ at higher frequencies in the soil parameter $Q_{f}$ represents the capacitive behaviour of the passive film formed at the surface, coupled with resistance due to ionic paths through oxide film $R_{f}$. Secondly, the process $\left(Q_{c t}, R_{c t}\right)$ is detected at low frequencies, $Q_{c t}$ represents the capacitive behavior at the electrolyte/metal interface (i.e. the double layer) and $R_{c t}$ represents the corresponding charge transfer resistance.

In the case of bronze, the corresponding equivalent circuit for EIS tests was shown in Fig. 2(c) There are two time constants in the equivalent circuit diagram that describe the corrosion process of bronze in sandy soil, where $R_{s}$ is the sandy soil resistance between working electrode and reference electrode, and $Q_{f} R_{f}$ represents the capacitance and resistance of the corrosion product film on the metal surface; $R_{c t}-Q_{l}$ corresponds to the charge transfer resistance and a constant phase element (CPE), and $W$ represents the Warburg diffusion impedance whose value can be expressed as:

$$
Z_{\omega}=\left(Y_{\omega}(j \omega)^{0.5}\right)^{-1}
$$

In the case of copper, the obtained impedances spectra exhibit three semicircles from high to low frequencies. So, two semicircles badly separated at high-frequency domain and the third one is at low-frequency domain. At high frequency (HF), the first semicircle may be attributed to the adsorbed specie, whereas the second one is the response of a combination of $R_{c t}$ and constant phase element (CPE). At low frequency (LF), the obtained loop is generally assigned to a slow transport process like diffusion $[17,18]$. However, the Warburg impedance is introduced because it reflects the diffusion process of dissolved oxygen from the soil to the electrode surface and/or the diffusion process of soluble copper species in the reverse sense. In addition, the capacitive semicircle is commonly assigned to the double-layer capacitance $\left(C_{c t}\right)$
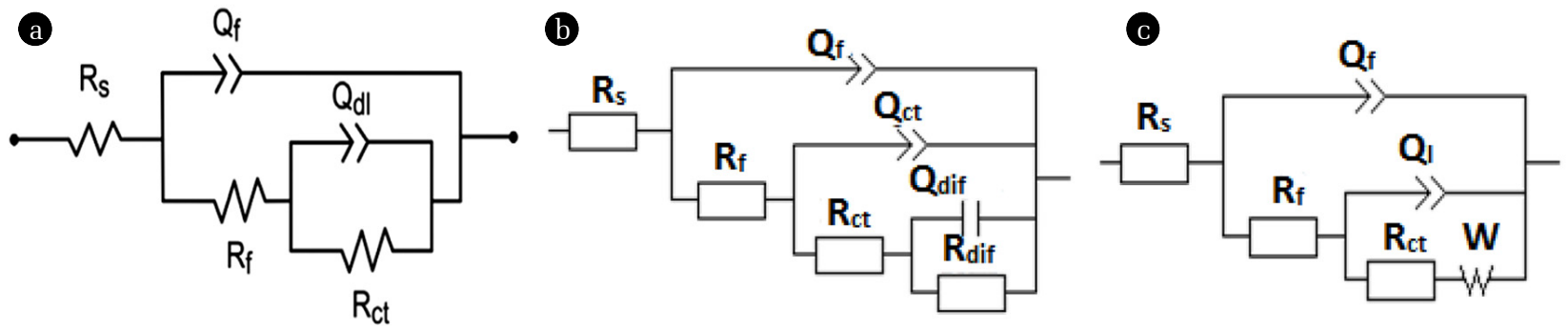

Fig. 2. Electrical equivalent circuit used for modeling the interface of (a) brass (b) copper (c) bronze / Essaouira soil with $20 \%$ of moisture. 

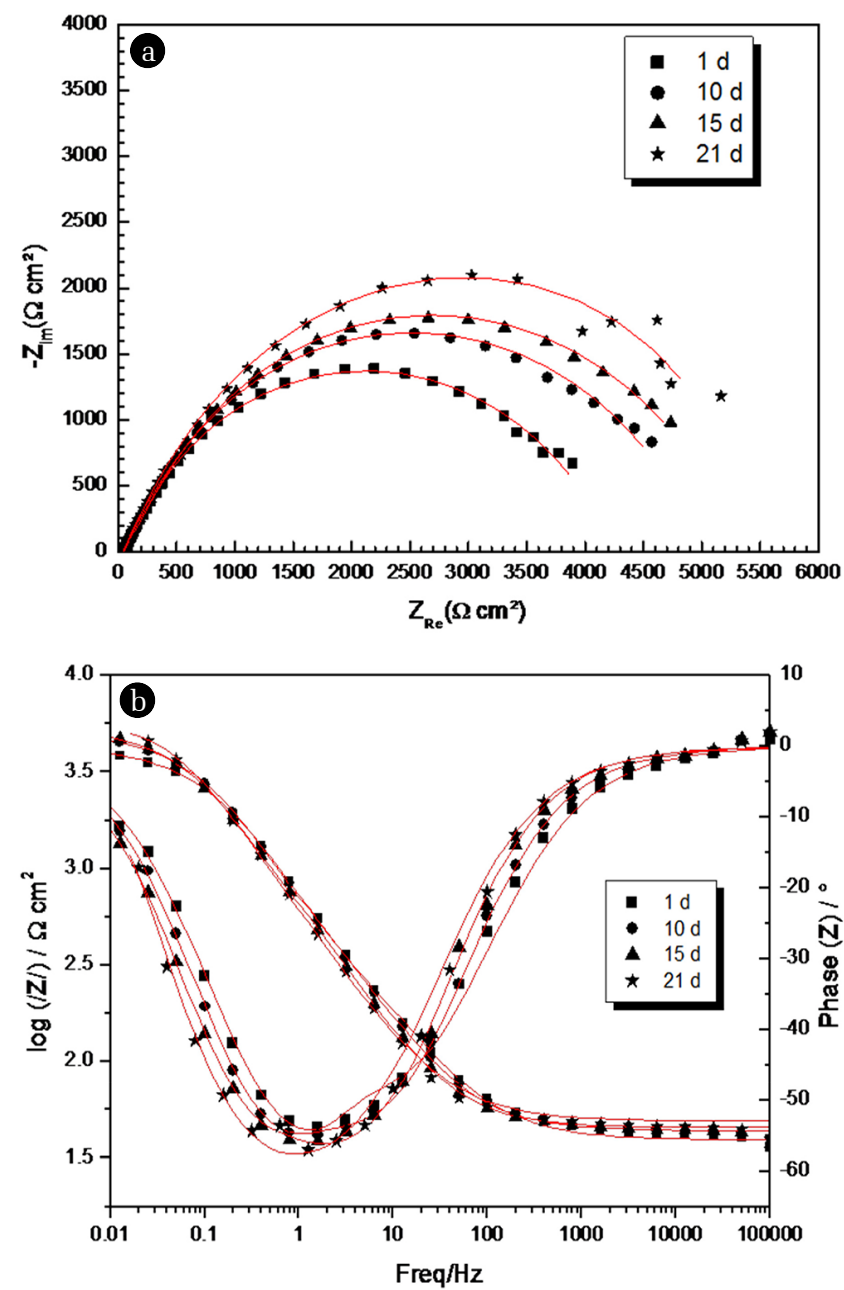

Fig. 3. Nyquist (a) and Bode (b) diagrams for brass in Essaouira soil with $20 \%$ of moisture content at different immersion times.

and charge transfer resistance $\left(R_{c t}\right)$. Deviations from a perfect circular shape (depression) are often related to the frequency dispersion of interfacial impedance arising from a lack of homogeneity of the electrode surface due to roughness or interfacial phenomena [19]. The proposed electrical circuit, as shown in Fig. 6, was used to describe the copper/electrolyte interface model. The employed circuit allowed for the identification of solution resistance $\left(R_{s}\right)$, charge transfer resistance $\left(R_{c t}\right)$ and resistance associated with the layer of products formed $\left(R_{f}\right)$. It is worthy of note that the double-layer capacitance $\left(C_{c t}\right)$ value was affected by imperfections of the surface, and this effect was simulated via a CPE $[20,21]$. The $Q_{c t}$ and $n$ parameters are employed in case the surface heterogeneity may affect them, this heterogeneity can be a result of surface roughness, corrosion product adsorption, and porous layer formation. Therefore, the expression differs from the CPE impedance frequently used nowadays, where the impedance of parallel connection of the CPE and $R$ will be expressed as [22]:

$$
Z_{C P E}=R /\left(1+R \times C P E(j \omega)^{n}\right)
$$
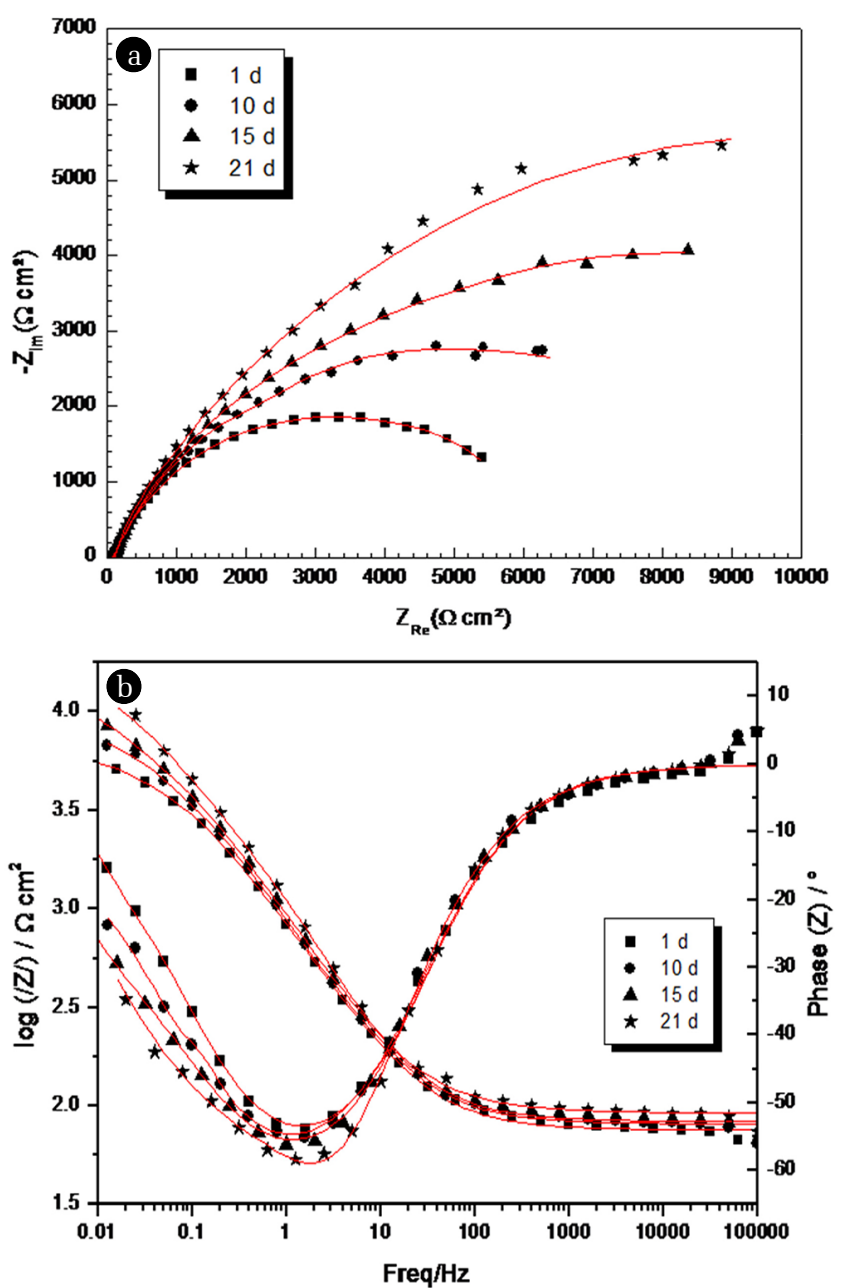

Fig. 4. Nyquist (a) and Bode (b) diagrams for bronze in Essaouira soil with $20 \%$ of moisture content at different immersion times.

For the former, the capacitance has the unit of $\mathrm{F}$ ( $\mathrm{or} \mathrm{F} \mathrm{cm}^{-2}$ ), whereas the later involves the remaining time dimension and $\mathrm{CPE}$ has the unit of $\mathrm{F} \mathrm{S}^{\mathrm{n}-1}$ or $\left(\mathrm{F} \mathrm{S}^{\mathrm{n}-1} \mathrm{~cm}^{-2}\right)$. Wheren is the coefficient representing the frequency dispersion of capacitive time.

EIS data analysis is based mainly on the carrying out of equivalent circuits in order to model the metal/electrolyte (in our study copper alloy/soil) interface to represent the experimental diagrams, various equivalent circuits were applied using a Bouckamp software [15].

Table 3 represents the estimated electrochemical impedance parameters for all electrodes corrosion in the studied soil with $20 \%$ of moisture contents at different immersion times. The The data used for polarization resistance $R_{p}$ of the studied systems are listed also in Table 3. Its value was calculated using the following equation:

$$
R_{p}=R_{f}+R_{c t}+R_{s}
$$

It is noted that the $R_{p}$ values of all brasses increase with the immersion time. The highest value of $R_{p}$ recorded of various 

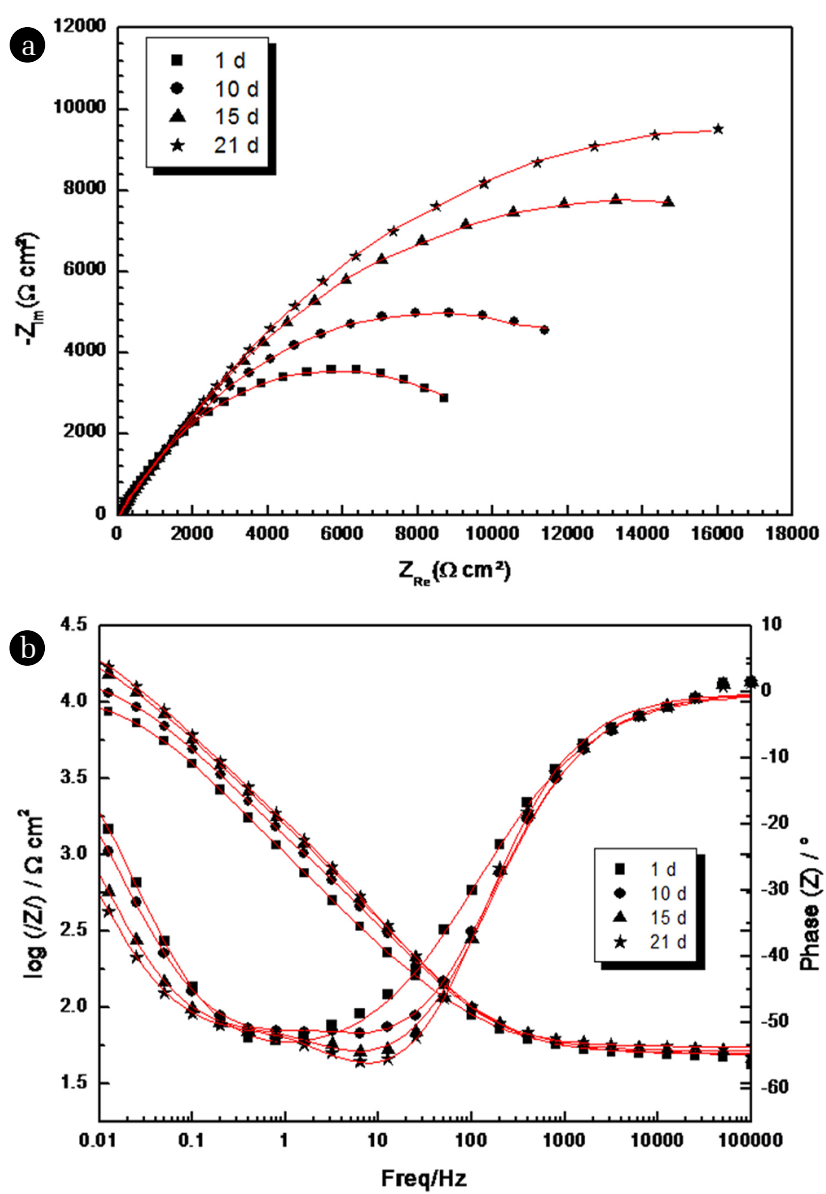

Fig. 5. Nyquist (a) and Bode (b) diagrams for copper in Essaouira soil with $20 \%$ of moisture content at different immersion times.

electrodes after $20 \mathrm{~d}$ of immersion can be attributed to the formation of a protective layer on the metallic surface which is related to the chemical composition of each electrode such as
$\mathrm{Cu}, \mathrm{Zn}$ and $\mathrm{Sn}$. A long immersion of these alloys in the soil media raises the resistance of its barrier film and becomes stable after $21 \mathrm{~d}$ of immersion in Essaouira soil.

However, it can be observed that the Warburg impedance disappears in the case of brass. Only some large convex arcs are observed in the Nyquist plots, demonstrating that brass corrosion is controlled by the charge transfer process in this condition [23].

It is noticed from Table 3 that the values of both $R_{c t}$ and $R_{f}$ increased with immersion time demonstrating that the protective film formed on copper and its alloys surface is composed of corrosion product. Furthermore, the values of $C_{f}$ and $C_{c t}$, which can be expressed below as Eq. (7) and (8) indicated in the study $[23,24]$ decrease with increasing immersion time.

$$
\begin{gathered}
C_{d l}=\frac{\varepsilon_{0} \times \varepsilon}{d} \times S \\
C_{f}=\frac{F^{2} \times S}{4 R T}
\end{gathered}
$$

Where $S$ is the surface area of electrode exposed in the corrosive medium (soil), $d$ is the thickness of electric double-layer, $F$ is the Faraday's constant. $\varepsilon_{0}$ and $\varepsilon$ are the permittivity of the air and the local dielectric constant, respectively. Therefore, the decrease of $C_{f}$ can be interpreted with the formation of the protective film, which reduces the exposed electrode surface area at the corrosive medium.

In addition, according to the results of parameter data obtained, we end in the following classification for the all electrodes as follows:

$$
\text { copper }>\text { bronze }>\text { brass }
$$

In this soil, the electrolyte resistance $\left(R_{s}\right)$ was found to increase with the immersion time. This increase can be related to the change in the composition of the soil which becomes less conductive due to the decrease in $\mathrm{Cl}^{-}$and $\mathrm{SO}_{4}{ }^{2-}$ ions which are

\begin{tabular}{|c|c|c|c|c|c|c|c|c|c|c|c|c|}
\hline \multirow{2}{*}{ Parameters } & \multicolumn{4}{|c|}{ Brass } & \multicolumn{4}{|c|}{ Bronze } & \multicolumn{4}{|c|}{ Copper } \\
\hline & $1^{*}$ & $10^{*}$ & $15^{*}$ & $21^{*}$ & $1^{*}$ & $10^{*}$ & $15^{*}$ & $21 *$ & $1^{*}$ & $10^{*}$ & $15^{*}$ & $21^{*}$ \\
\hline $\mathrm{R}_{\mathrm{s}}\left(\Omega \mathrm{cm}^{2}\right)$ & 40 & 43 & 45 & 50 & 75 & 81 & 84 & 92 & 48 & 50 & 51 & 50 \\
\hline $\mathrm{Q}_{\mathrm{f}}\left(\mu \mathrm{F} \mathrm{cm}^{-2}\right)$ & 294 & 310 & 236 & 312 & 111 & 395 & 98 & 76 & 450 & 126 & 280 & 240 \\
\hline$\alpha_{\mathrm{f}}$ & 0.71 & 0.73 & 0.74 & 0.71 & 0.72 & 0.72 & 0.74 & 0.78 & 0.61 & 0.94 & 0.95 & 0.95 \\
\hline $\mathrm{R}_{\mathrm{f}}\left(\Omega \mathrm{cm}^{2}\right)$ & 1,088 & 2,201 & 2,309 & 2,518 & 713 & 380 & 6,577 & 6,950 & 20 & 70 & 165 & 840 \\
\hline $\mathrm{Q}_{\mathrm{ct}}\left(\mu \mathrm{F} \mathrm{cm}^{-2}\right)$ & 61 & 93 & 57 & 49 & 314 & 306 & 297 & 95 & 174 & 141 & 130 & 121 \\
\hline$\alpha_{\mathrm{ct}}$ & 1 & 1 & 1 & 0.97 & 1 & 1 & 0.72 & 0.78 & 0.57 & 0.73 & 0.73 & 0.77 \\
\hline $\mathrm{R}_{\mathrm{ct}}\left(\Omega \mathrm{cm}^{2}\right)$ & 3,122 & 3,067 & 3,183 & 3,350 & 5,672 & 9,169 & 9,681 & 12,450 & 1,226 & 1,828 & 3,265 & 2,508 \\
\hline $\mathrm{S}\left(\Omega \mathrm{s}^{-1 / 2}\right)$ & - & - & - & - & 26 & 221 & 75 & 50 & - & - & - & - \\
\hline $\mathrm{Q}_{\mathrm{dif}}\left(\mu \mathrm{F} \mathrm{cm}^{-2}\right)$ & - & - & - & - & - & - & - & - & 166 & 124 & 123 & 121 \\
\hline$\alpha_{\text {dif }}$ & - & - & - & - & - & - & - & - & 0.66 & 0.66 & 0.67 & 0.64 \\
\hline $\mathrm{R}_{\mathrm{dif}} /\left(\Omega \mathrm{cm}^{2}\right)$ & - & - & - & - & - & - & - & - & 10,392 & 14,809 & 22,852 & 30,410 \\
\hline $\mathrm{R}_{\mathrm{p}}\left(\Omega \mathrm{cm}^{2}\right)$ & 4,209 & 5,268 & 5,492 & 5,868 & 5,672 & 9,169 & 16,258 & 19,310 & 11,618 & 16,637 & 26,117 & 32,919 \\
\hline
\end{tabular}
deposited on electrode surface to form corrosion products.

Table 3. Electrochemical Impedance Parameters of All Electrode in Essaouira Soil with $20 \%$ of Moisture Content at Different Immersion Times

"time in days 


\subsection{Potentiodynamic Polarization}

Fig. 6 shows the polarization curves obtained on a large potential range (from $1,500 \mathrm{mV} / \mathrm{Cu} / \mathrm{CuSO}_{4}$ to $1,200 \mathrm{mV} / \mathrm{Cu} / \mathrm{CuSO}_{4}$ ) at the end of the $21 \mathrm{~d}$ of immersion for the three electrodes under investigation in the Essaouira soil at $20 \%$ of moisture content. Their corresponding parameters like potential of corrosion $\left(E_{\text {corr }}\right)$, anodic $\left(\beta_{\mathrm{a}}\right)$ and cathodic $\left(\beta_{\mathrm{c}}\right)$ Tafel slopes, and corrosion current density $\left(i_{\text {corr }}\right)$ of all studied systems were fitting by equation of Stern-Geary and registered in Table 4.

Fig. 7 shows the simulation results of the cathodic and anodic branches for different electrodes in sandy soil after an immersion of $21 \mathrm{~d}$. In this simulation, the potential domain is in the vicinity of corrosion potential, $\mathrm{E}_{\text {corr }}+-100 \mathrm{mV}$. The calculated data agrees with the experimental polarization data in Fig. 6 .

It can be seen from Fig. 6 that besides the $\mathrm{E}_{\text {corr }}$ (region (I)) the charge transfer and mass transport are both the factors which control kinetics are commonly assumed and thus the Tafel behavior

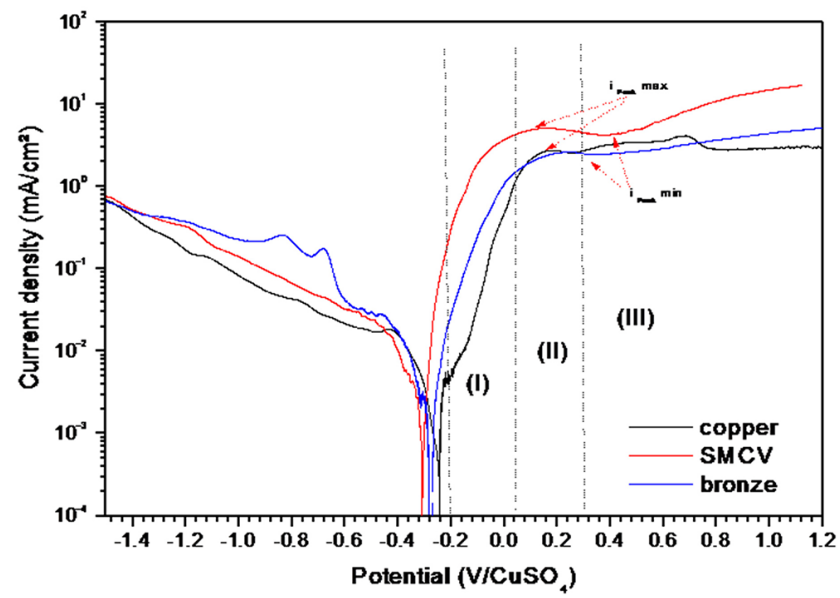

Fig. 6. Polarization curves for different electrode after $21 \mathrm{~d}$ of immersion in Essaouira soil with $20 \%$ of moisture content.

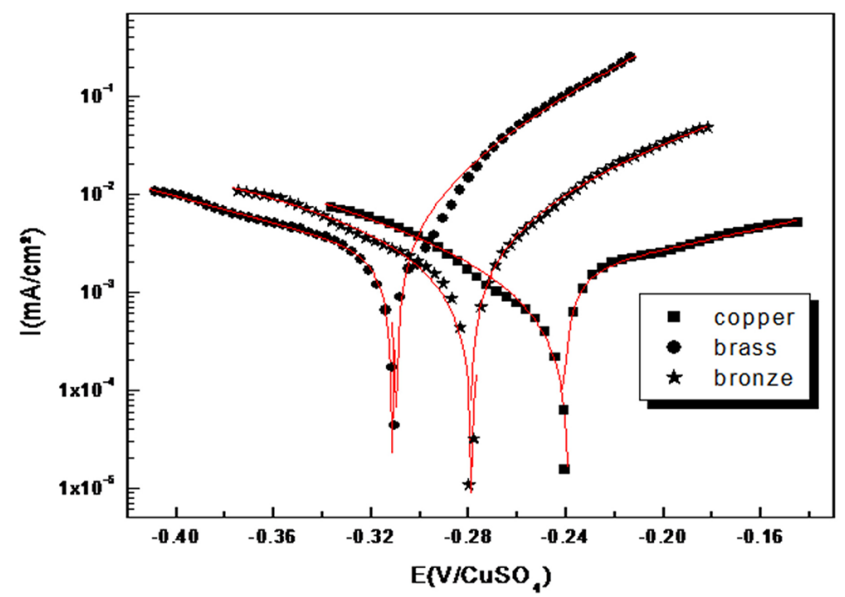

Fig. 7. Comparison of experimental (scatter) and fitting (red line) data using a nonlinear fitting with Stern-Geary equation for different electrode after $21 \mathrm{~d}$ of immersion in Essaouira soil with 20\% of moisture content. of the curve is only "apparent". In region (II), we can notice the appearance of a peak in all anodic part (peak current density $\left(i_{\text {peak }}\right)$ ). In this peak, the current density decreases due to the formation of a $\mathrm{CuCl}$ film [25]. In region (III), the potential increases again before stabilizing (passive region). This region is about $0.9 \mathrm{~V}$ from $+0.3 \mathrm{~V}$ to $+1.2 \mathrm{~V}$ over which the current density is constant. This plateau is attributed to the formation of protective oxide film on surfaces of samples [26].

In general, the corrosion of $\mathrm{Cu}$ alloys, in neutral chloride solutions, involves the cathodic reduction of oxygen:

$$
\mathrm{O}_{2}+2 \mathrm{H}_{2} \mathrm{O}+4 \mathrm{e}^{-} \rightarrow 4 \mathrm{OH}^{-}
$$

In the anodic region, the dissolution of copper alloys in the medium containing the chloride ions, generates the following steps:

- Spontaneous dissolution of copper oxide $\mathrm{Cu}_{2} \mathrm{O}$ formation:

$$
2 \mathrm{Cu}+\mathrm{H}_{2} \mathrm{O} \rightarrow \mathrm{Cu}_{2} \mathrm{O}+2 \mathrm{H}^{+}+2 \mathrm{e}^{-}
$$

- When the surface is covered with $\mathrm{Cu}_{2} \mathrm{O}$ and $\mathrm{ZnO}, \mathrm{CuCl}$ is then formed on the surface according to the reaction:

$$
\mathrm{Cu}^{+}+\mathrm{Cl}^{-} \rightarrow \mathrm{CuCl}
$$

This last $\mathrm{CuCl}$ can transform into $\mathrm{CuCl}_{2}$ according to the reaction: [27-29]

$$
2 \mathrm{CuCl} \rightarrow \mathrm{Cu}+\mathrm{CuCl}_{2}
$$

or dissolves with the formation of $\mathrm{CuCl}_{2}^{-}$complex via: [27-29]

$$
\mathrm{CuCl}+\mathrm{Cl}^{-} \rightarrow \mathrm{CuCl}_{2}^{-}
$$

The values of the current density of the three different electrodes were calculated at the same soil. Under the same conditions, copper is the most resistant electrode in this soil. The corrosion rate of the copper is less than 3 and 4 times in comparison with the bronze and brass respectively and we can follow this classification:

$$
\text { copper }>\text { bronze }>\text { brass }
$$

We can explain this classification as follows:

The brasses will be sensitive to dezincification process when the zinc components are higher than 15\% [30]. In another study

\begin{tabular}{|c|c|c|c|c|}
\hline \multirow{2}{*}{$\begin{array}{l}\text { Brass } \\
\text { grad }\end{array}$} & \multirow{2}{*}{$\begin{array}{c}\mathrm{E}_{\text {corr }} \\
\left(\mathrm{mV} / \mathrm{Cu} / \mathrm{CuSO}_{4}\right)\end{array}$} & \multicolumn{2}{|c|}{ Tafel plot $(1 / \mathrm{mV})$} & \multirow{2}{*}{$\begin{array}{c}\mathbf{I}_{\text {corr }} \\
\left(\mu \mathrm{A} / \mathbf{c m}^{2}\right)\end{array}$} \\
\hline & & $\boldsymbol{\beta}_{\mathbf{a}}$ & $-\boldsymbol{\beta}_{\mathrm{c}}$ & \\
\hline SMCV & -311 & 21.77 & 15.68 & 10.3 \\
\hline Bronze & -278 & 12.12 & 4.35 & 6.8 \\
\hline Copper & -239 & 12.23 & 9.4 & 2.3 \\
\hline
\end{tabular}
by Lucey [31], two mechanisms have been proposed for dezincification of brass:

Table 4. Polarization Curves Parameters for Different Electrode after 21 Days of Immersion in Essaouira Soil with $20 \%$ of Moisture Content 
- the first mechanism suggests that the $\mathrm{Zn}$ is leached out of the alloy.

- the second mechanism proposes that the entire alloy dissolves, but the $\mathrm{Cu}$ is redeposited on the surface.

Moreover, in this research, the bronze is more resistant compared with brass due to the chemical composition of bronze which contains a lower percentage of zinc $5 \%$. The presence of tin in bronze with $5 \%$ improves resistance to corrosion due to the formation of Sn compounds that cover the surface and confer to the interface a blocking behavior.

\subsection{Characterization of Corrosion Layers by SEM-EDS Analysis}

The study of electrochemical behavior is not sufficient to explain the degradation process. Therefore, to have a very deep understanding of degradation process, we have to connect this process to the structure and composition of the corrosion product layer which is formed on surface alloys. SEM-EDS analysis was done on three electrodes. Fig. 8, 9 and 10 give the corresponding SEM images of bronze, brass and copper respectively under investigation after $130 \mathrm{~d}$ of immersion in sandy soil at $20 \%$ of moisture

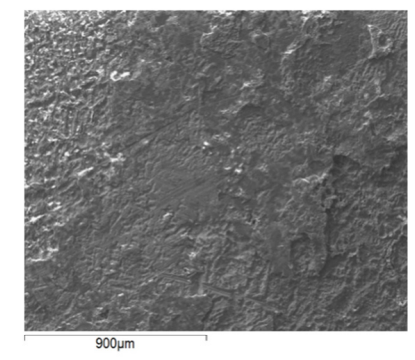

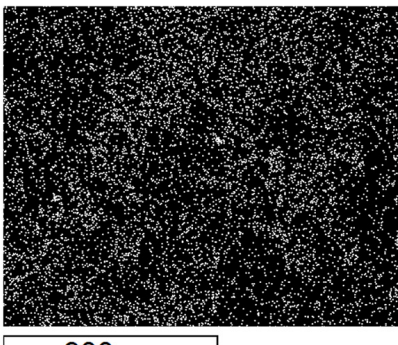

$900 \mu \mathrm{m}$

$\mathrm{C}$

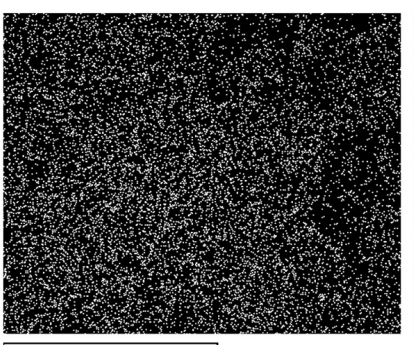

$900 \mu \mathrm{m}$

$\mathrm{Zn}$

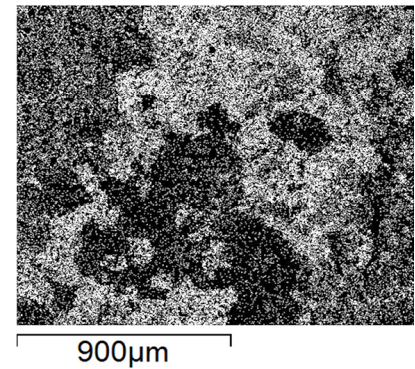

$\mathrm{Ca}$

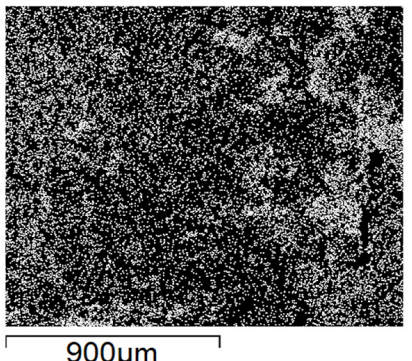

$900 \mu \mathrm{m}$

$\mathrm{Cl}$

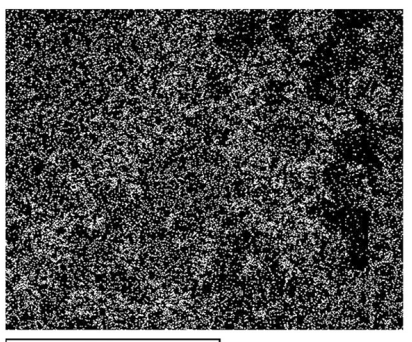

$900 \mu \mathrm{m}$

$\mathrm{Sn}$

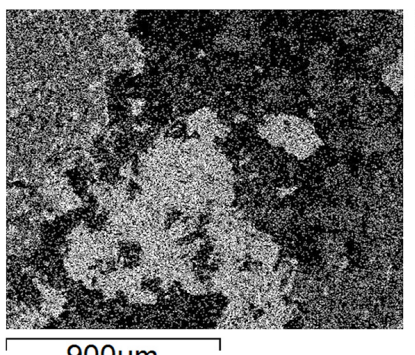

$900 \mu \mathrm{m}$

$\mathrm{Cu}$

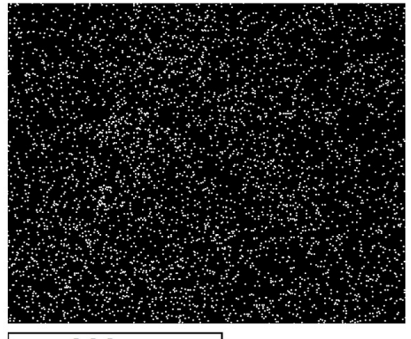

$900 \mu \mathrm{m}$

$\mathrm{Pb}$

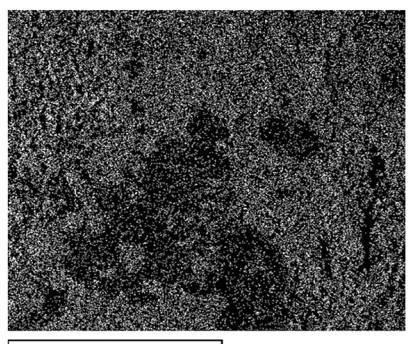

$900 \mu \mathrm{m}$

O

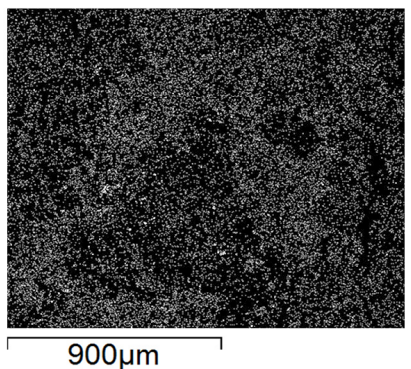

S

Fig. 8. SEM analysis microanalysis of the corroded surface after $130 \mathrm{~d}$ of immersion in sandy soil Essaouira at $20 \%$ of moisture content for bronze. 
content. The data of EDS analysis of the corrosion product formed on the each electrode surface are presented in Table 5 .

Observed differences between copper, bronze and the copper exposed in Essaouira soil at 20\% of moisture content were evident not only from differences in visual appearance, measured corrosion rates and polarization resistance, but also from the analysis and characterization of corrosion products, illustrated after 130 $\mathrm{d}$ of immersion. The copper surface immersed in soil (Fig. 10) shows a large area free of corrosion products and the surface is intact as the polishing stripes remained perfectly visible on it even after exposure. The surface of bronze (Fig. 8) observed was uniform, compact and covered with a corrosion product. In other words, the film seems to be more compact and thicker on the surface. The observation of brass surface (Fig. 9) reveals peeling of the surface layer (cracked layers). Furthermore, it is noticed that the corroded surface shows many pits; consequently, this porous structure and the presence of the crevices in the corrosion layer produced the channels which let the diffusion of elements of corrosive medium (water, oxygen, salt ions and other corrosive media) through metal substrate [32].

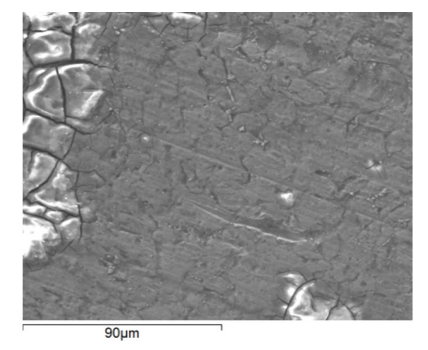

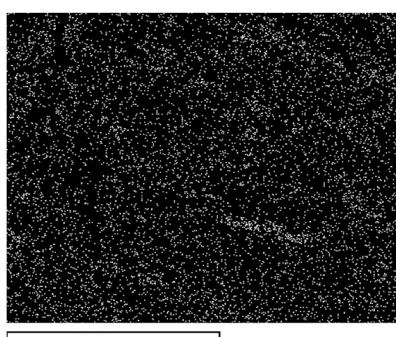

$90 \mu \mathrm{m}$

C

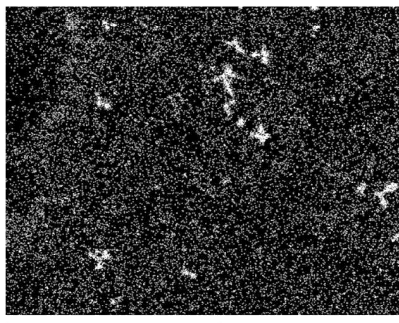

$90 \mu \mathrm{m}$

$\mathrm{Fe}$

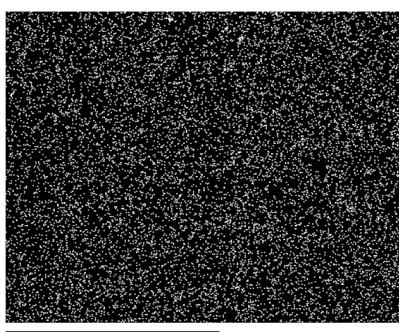

$90 \mu \mathrm{m}$

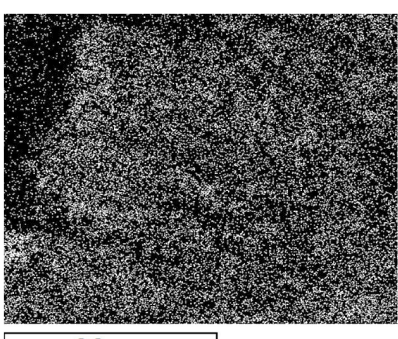

$90 \mu \mathrm{m}$

$\mathrm{Cl}$

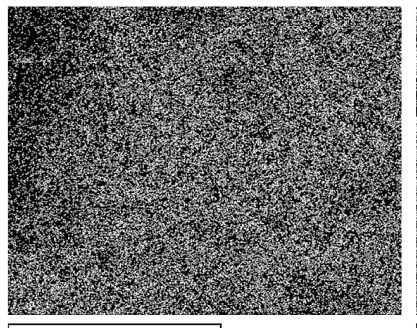

$90 \mu \mathrm{m}$

$\mathrm{Zn}$

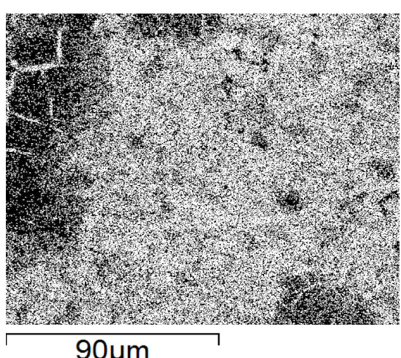

$\mathrm{Cu}$

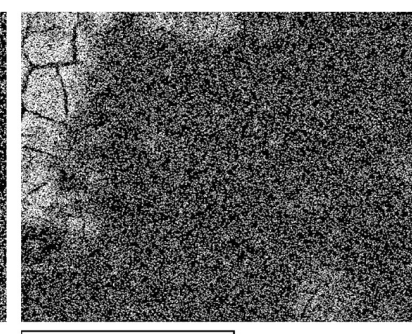

$90 \mu \mathrm{m}$

Al

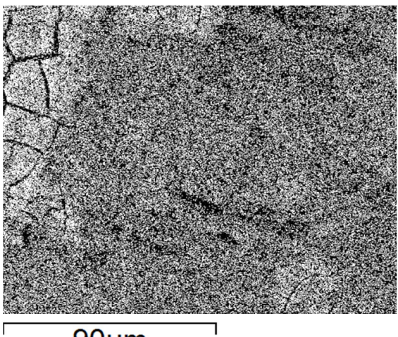

$90 \mu \mathrm{m}$

O

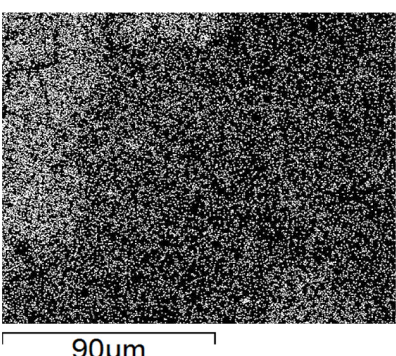

$90 \mu \mathrm{m}$

S

Fig. 9. SEM analysis microanalysis of the corroded surface after $130 \mathrm{~d}$ of immersion in sandy soil Essaouira at $20 \%$ of moisture content for brass. 

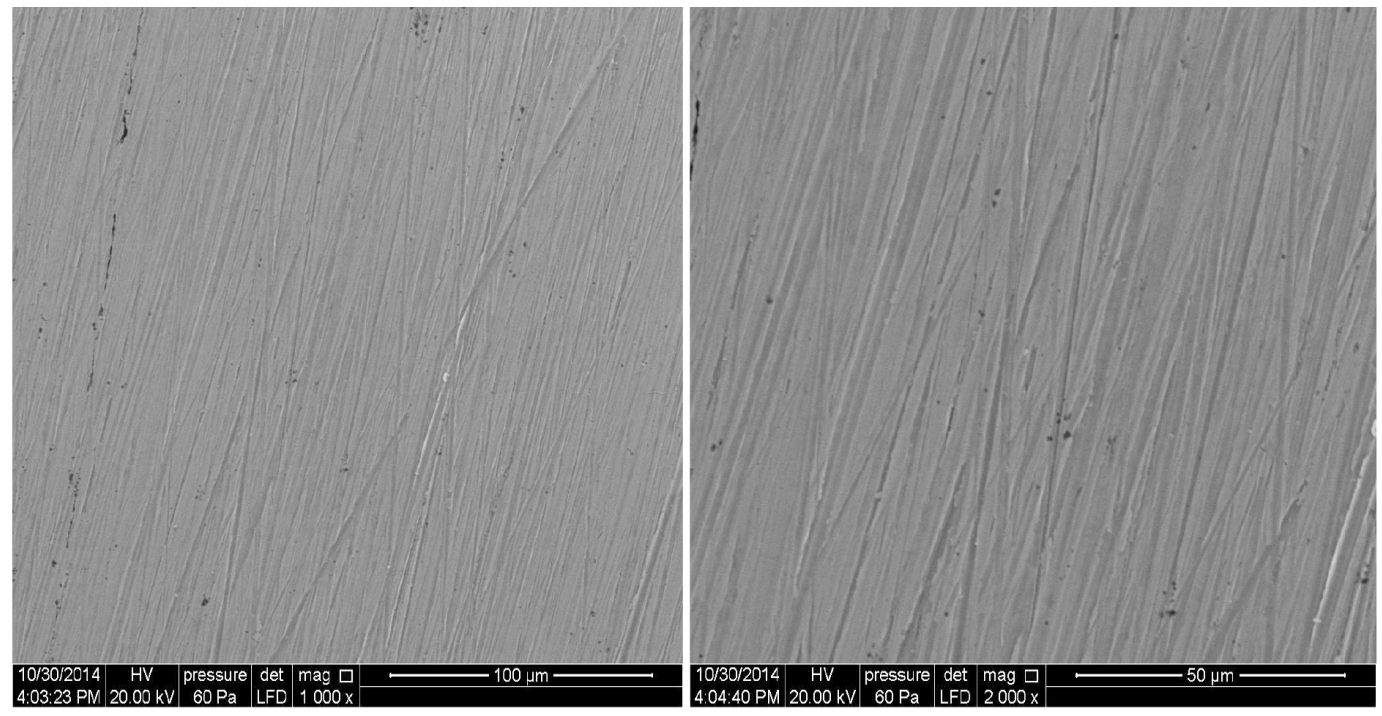

Fig. 10. SEM analysis microanalysis of the corroded surface after $130 \mathrm{~d}$ of immersion in sandy soil Essaouira at $20 \%$ of moisture content for copper.

Table 5. The Composition of the Corrosion Layer Formed on Surface in Each Electrode After 130 Days of Immersion in Sandy Soil Essaouira at $20 \%$ of Moisture Content

\begin{tabular}{cccc}
\hline Element/Weight/\% & Bronze & Brass & Copper \\
\hline $\mathrm{C}$ & 10.33 & 7.68 & - \\
$\mathrm{O}$ & 29.47 & 27.87 & 2.53 \\
$\mathrm{Na}$ & - & 2.19 & - \\
$\mathrm{Mg}$ & 0.28 & 0.13 & - \\
$\mathrm{Al}$ & 0.21 & 4.48 & - \\
$\mathrm{Si}$ & 0.62 & 0.59 & - \\
$\mathrm{S}$ & 0.36 & 1.06 & 0.33 \\
$\mathrm{Cl}$ & 1.68 & 1.59 & - \\
$\mathrm{Ca}$ & 6.47 & 0.11 & - \\
$\mathrm{Mn}$ & - & 0.12 & - \\
$\mathrm{Fe}$ & 0.16 & 2.52 & - \\
$\mathrm{Ni}$ & 0.69 & 0.40 & - \\
$\mathrm{Cu}$ & 33.15 & 35.69 & 97.13 \\
$\mathrm{Zn}$ & 4.48 & 14.88 & - \\
$\mathrm{Mo}$ & 0.00 & - & - \\
$\mathrm{Sn}$ & 6.55 & 0.60 & - \\
$\mathrm{Pb}$ & 5.55 & - & - \\
\hline
\end{tabular}

The EDAX analysis was employed to determine the elemental composition of corrosion products formed on surface of the three samples after $130 \mathrm{~d}$ of immersion in sandy soil Essaouira. The results of this analysis are shown in Table 5. These data show that copper surface contains a large percentage of $\mathrm{Cu}$ with a lower percentage of oxygen which explains the presence of $\mathrm{Cu}$ oxides but with very little percentage. In the case of the bronze primary elements detected were $\mathrm{Zn}, \mathrm{Cu}, \mathrm{O}$ and $\mathrm{Cl}$ along with,
$\mathrm{Ca}, \mathrm{C}, \mathrm{Sn}, \mathrm{Pb}$, etc. Main corrosion products are expected to be oxides and chlorides of $\mathrm{Zn}$ and $\mathrm{Cu}$. The higher percentage of $\mathrm{Sn}$ on the surface of bronze indicates that Sn agglomerated at the corrosion product/metal interface and then formed a passive film which increases the resistance of bronze to generalized corrosion [33].

Concerning the brass, the EDAX shows that the corrosion product contains a large percentage of $\mathrm{Cu}$ and $\mathrm{Zn}$ with a high percentage of oxygen which explains the presence of $\mathrm{Cu}$ and $\mathrm{Zn}$ under oxides form. In addition, the presence of the $\mathrm{Al}, \mathrm{Ni}$, $\mathrm{Mn}$ and $\mathrm{Fe}$ (additional element in brass compositions) on the surface of corrosion product approves the surface degradation and consequently the corrosion rate becomes greater. Moreover, soil elements such as $\mathrm{Fe}, \mathrm{Si}, \mathrm{Ca}, \mathrm{S}, \mathrm{Mg}, \mathrm{C}$ are detected in the corrosion product. The results that are obtained by EDAX and scanning electron microscopy are in agreements with those of the polarization and impedance measurements.

\section{Conclusions}

Comparative analysis for the corrosion susceptibility of copper, bronze, and brass in the soil of Essaouira field was evaluated at ambient temperature using polarization curves and EIS that were associated with SEM and EDAX techniques. The following points give the most important remarks that can be concluded from this research:

- Polarization resistance $R_{p}$ of all samples increase with the immersion time in sandy soil. This is assigned to the formation of a protective film on the surface of each electrode. This protective film is related to the chemical composition of alloys such as $\mathrm{Cu}, \mathrm{Zn}, \mathrm{P}$, As and $\mathrm{Sn}$ which transformed to the oxide film.

- $R_{s}$ was found to increase with the immersion time; this increase could be related to the soil which becomes less 
conductive due to the $\mathrm{Cl}^{-}$and $\mathrm{SO}_{4}{ }^{2-}$ ions concentration decrease. As a matter of fact, Chloride ions tend to dissolve many metals specially at acidic $\mathrm{pH}$. Besides, the soil resistivity also decreases because of their concentration.

- The corrosion rate of the copper is less than 3 and 4 times in comparison with the bronze and brass, respectively.

- All measurements concluded that the possible corrosion of the studied materials can be classified in this order :

$$
\text { copper }>\text { bronze }>\text { brass. }
$$

- SEM for the surface of the studied materials after $130 \mathrm{~d}$ of immersion revealed that a corrosion layer was formed with density dependence on the metal type.

The results that are obtained by EDAX and scanning electron microscopy are in agreement with those of the polarization and impedance measurements.

\section{References}

1. Schutze M, Feser R, Bender R. Corrosion resistance of copper and copper alloys. Dechema eV Society for Chemical Engineering and Biotechnology; 2011. p. 752.

2. Davies DD. A note on the dezincification of brass and the inhibiting effect of elemental additions. New York: Copper Development Association; 1993. p. 1-9.

3. Polan NW. Corrosion, metals handbook. 9th ed. ASTM International: Metals Park, Ohio; 1987. p. 614.

4. Dermaj A, Hajjaji N, Joiret S, et al. Electrochemical and spectroscopic evidences of corrosion inhibition of bronze by a triazole derivative. Electrochim. Acta. 2007;52:4654-4662.

5. Gerwin W, Baumhauer W. Effect of soil parameters on the corrosion of archaeological metal finds. Geoderma 2000;96: 63-80.

6. Papadopoulou O, Vassiliou P, Grassini S, Angelini E, Gouda V. Soil-induced corrosion of ancient Roman brass - A case study. Mater. Corros. 2016;67:160-169.

7. Tylecote RF. The effect of soil conditions on the long-term corrosion of buried tin-bronzes and copper. J. Archaeol. Sci. 1979;6:345-368.

8. Neff D, Dillmann P, Bellot-Gurlet L, Beranger G. Corrosion of iron archaeological artefacts in soil: Characterisation of the corrosion system. Corros. Sci. 2005;47:515-535.

9. Li M, Lin H, Cao C. Influence of moisture content on soil corrosion behavior of carbon steel. Corros. Sci. Prot. Technol. 2000;12:219-221.

10. Wu YH, Sun C, Zhang SQ, Cai DC, Li GH, Liu X. Influence of soil humidity on corrosion behavior of X70 pipeline steel in saline soils of Qinghai salt lake region. Corros. Sci. Prot. Technol. 2005;17:87-90.

11. Fei XD, Li MQ, Xu HM, Li YQ, Cai DC. Influence of soil humidity on corrosion behavior of X70 steel in yellow pebble soil. Corros. Sci. Prot. Technol. 2007;19:35-37.

12. Mincheol K, Inakazu T, Koizumi A, Koo J. Statistical approach for corrosion prediction under fuzzy soil environment. Environ. Eng. Res. 2013;18:37-43.
13. Galai M, Benqlilou H, Ebn Touhami M, et al. Nitrate effect on degradation processes of $\alpha,(\alpha+\beta)$-brasses in Moroccan Azrou soil medium. Anal. Bioanal. Electrochem. 2017;9:673-688.

14. Galai M, Ouassir J, Ebn Touhami M, et al. $\alpha$-brass and $(\alpha+\beta)$ brass degradation processes in Azrou soil medium used in plumbing devices. J. Bio. Tribo. Corros. 2017;3:30.

15. Boukamp A. Users manual equivalent circuit. ver. 4.51. the Netherlands: University of Twente; 1993.

16. Raistrick ID, MacDonald JR, Francschetti DR. Impedance spectroscopy emphasizing solid materials and systems. New York: John Wiley \& Sons; 1987. Chapter 2.

17. Amar H, Benzakour J, Derja A, Villemin D, Moreau B, Braisaz T. Piperidin-1-yl-phosphonic acid and (4-phosphonopiperazin1-yl) phosphonic acid: A new class of iron corrosion inhibitors in sodium chloride 3\% media. Appl. Surf. Sci. 2006;252: 6162-6172.

18. Touir R, Dkhireche N, EbnTouhami M, et al. Study of phosphonate addition and hydrodynamic conditions on ordinary steel corrosion inhibition in simulated cooling water. Mater. Chem. Phys. 2010;122:1-9.

19. Bouyanzer A, Hammouti B, Majidi L. Pennyroyal oil from Mentha pulegium as corrosion inhibitor for steel in $1 \mathrm{M} \mathrm{HCl}$. Mater. Lett. 2006;60:2840-2843.

20. Emregul KC, Hayvali M. Studies on the effect of a newly synthesized Schiff base compound from phenazone and vanillin on the corrosion of steel in $2 \mathrm{M} \mathrm{HCl}$. Corros. Sci. 2006;48:797-812.

21. Benabdellah M, Souane R, Cheriaa N, Abidi R, Hammouti B, Vicens J. Synthesis of calixarene derivatives and their anticorrosive effect on steel in 1M HCl. Pigm. Resin Technol. 2007;36:373-381.

22. Marušica K, curkovi 'c HO, Takenouti H. Inhibiting effect of 4-methyl-1-p-tolylimidazole to the corrosion of bronze patinatedinsulphate medium. Electrochim. Acta. 2011;56: 7491-7502.

23. Wang D, Xiang B, Liang Y, Song S, Liu C. Corrosion control of copper in 3.5 wt.\% $\mathrm{NaCl}$ solution by domperidone: Experimental and theoretical study. Corros. Sci. 2014;85: 77-86.

24. Li W, Hu L, Zhang S, Hou B. Effects of two fungicides on the corrosion resistance of copper in $3.5 \% \mathrm{NaCl}$ solution under various conditions. Corros. Sci. 2011;53:735-745.

25. Kear G, Barker BD, Walsh FC. Electrochemical corrosion of unalloyed copper inchloride media a critical review. Corros. Sci. 2004;46:109-135.

26. Sadawy MM, Ghanem M. Grain refinement of bronze alloy by equal-channel angular pressing (ECAP) and its effect on corrosion behaviour. Defence Technol. 2016;12:316-323.

27. Bacarella AL, Griess JC. The anodic dissolution of copper in flowing sodium chloride solutions between $25^{\circ}$ and $175^{\circ} \mathrm{C}$. J. Electrochem. Soc. 1973;120:459-465.

28. Chawla SK, Rickett BI, Sankarraman N, Payer JH. An X-ray photo-electronspectroscopic investigation of the air-formed film on copper. Corros. Sci. 1992;33:1617-1631.

29. Badawy WA, AL-Kharafi FM. Corrosion behavior of brass alloys in aqueous solutions of different pH. Corros. Sci. 1999;55:268-277. 
30. Assouli B. Etude par émission acoustique associée aux méthodes électrochimiques de la corrosion et de la protection de l'alliage cuivre-zinc (60/40) en milieu neutre et alcalin [thesis]. INPT, France. 2002.

31. Lucey VF. The mechanism of dezincification and the effect of arsenic. Brit. Corros. J. 1965;1:53-59.
32. He B, Han P, Lu C, Bai XH. Effect of soil particle size on the corrosion behavior of natural gas pipeline. Eng. Fail. Anal. 2015;58:19-30.

33. Sohn S, Kang T. The effects of tin and nickel on the corrosion behavior of $60 \mathrm{Cu}-40 \mathrm{Zn}$ alloys. J. Alloy. Compd. 2002;335: 281-289. 